\title{
Dependence on policy revenue poses risks for investments in dairy digesters
}

California dairy farms face policy uncertainties over investments in anaerobic manure digestion to produce methane for renewable, low-carbon vehicle fuel.

by Hyunok Lee and Daniel A. Sumner

\section{Abstract}

Manure-sourced methane emissions from livestock operations in California will soon be subject to new regulation, as required by Senate Bill 1383, which was signed into law in 2016. Regulations, beginning in 2024, will require reductions in methane emissions from livestock manure, with a $40 \%$ reduction target by 2030 . The California dairy industry accounts for most of the manure-sourced methane emissions in the state and, in order to reduce these emissions, government experts and authorities have encouraged expansion of anaerobic digestion of dairy waste - especially to produce transportation fuel. Renewable natural gas for vehicle fuel, produced from manure at digesters, is eligible for substantial federal and California environmental credits, which are now projected to contribute the bulk of the revenue for qualifying digesters. This article shows that investments in digesters, because they depend heavily on revenue created by government policy, rather than on market-based sales of natural gas, are highly vulnerable to the risk of policy change or even minor technical adjustments in environmental regulations. Without secure projections of revenue that will cover costs, regulations may cause increases in the shift of milk production out of California.
$\mathrm{M}$ ilk is central to California's agricultural sector and the state is central to the U.S. dairy industry. Milk is the largest California farm commodity by sales value and California is the nation's top dairy state, with substantial overseas exports of milk products. However, the dairy industry faces many economic and policy challenges, none of which is more vital than how to deal with myriad environmental concerns and related regulations. Water and air quality issues have drawn the attention of state authorities such as the California Department of Food and Agriculture (CDFA), the California Air Resources Board (CARB) and the California State Water Resources Control Board. CDFA and CARB, among other agencies, are in the midst of an aggressive attempt to reduce greenhouse-gas emissions from agricultural production and processing. Their regulatory proposals are designed to meet legislative mandates while minimizing negative economic impacts.

Under a recently passed law that is now in the implementation process, California livestock farms will

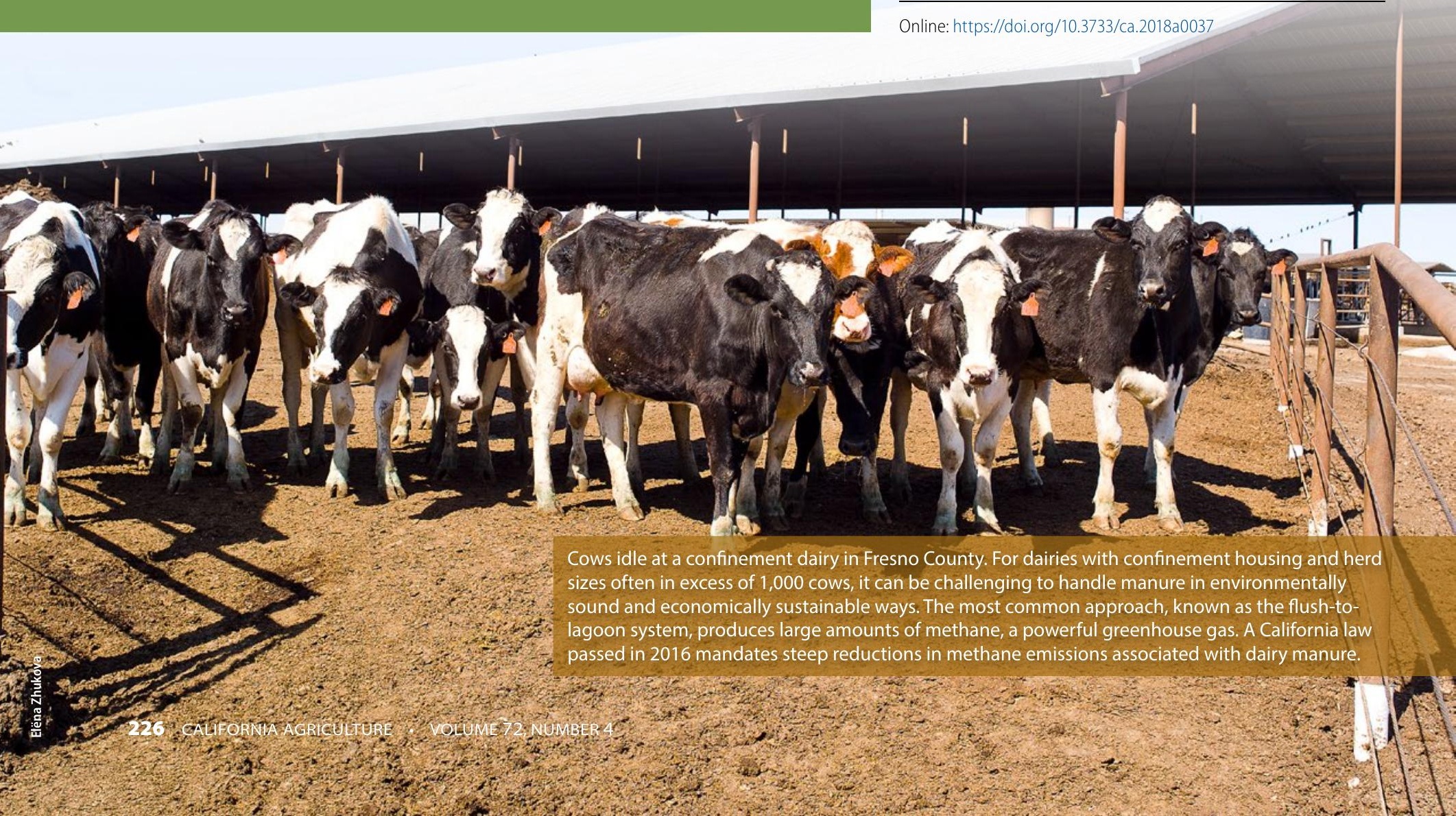


soon be subject to state regulations on greenhouse-gas emissions. As mandated by Senate Bill (SB) 1383 (Lara 2016), which was signed into law on September 19, 2016, methane emissions associated with manure produced at California livestock operations will be subject to detailed regulations, which will be phased in beginning in 2024.

The California livestock industry — particularly the dairy industry - is a significant contributor to the state's methane emissions. Methane is produced and emitted when ruminants digest by enteric fermentation and when livestock manure decomposes under anaerobic conditions. Livestock manure management has been subject to federal, state and local environmental regulations for many years, but regulation to mitigate methane emissions is new. SB 1383 calls for mandatory regulation of manure-sourced methane emissions by 2024 in order to reach a $40 \%$ reduction of greenhouse-gas emissions by 2030. Implementation of such regulations is conditional on economic feasibility among other conditions (Lara 2016). Enteric fermentation, although a larger source of methane emissions in California, is not yet subject to regulation.

Prior to the passage of SB 1383, in response to a legislative request, CARB initiated a study to develop comprehensive strategies for controlling short-lived climate pollutants, one of which is methane. Among several possible technologies for controlling manure-sourced emissions, CARB identified as most favorable a system of centralized digesters that would produce pipelineinjectable biomethane or renewable natural gas. CARB determined that such a system would be more favorable than the alternatives - not only financially but also in terms of achieving the large-scale methane reductions that are required by SB 1383 (CARB 2017). The system would be comprised of 55 digesters that would each collect manure from a cluster of nearby farms, process that manure and produce marketable methane. Under CARB's scenario, such a system would operate in the heart of the San Joaquin Valley's intensive dairy region - allowing economies of scale while still limiting the cost of manure transport.

Alternatives considered by CARB included a system in which a digester on each farm would produce biogas that would be piped at low pressure to a locally centralized facility - which in turn would process the biogas, producing renewable natural gas for vehicle fuel. That system would entail some advantages, such as enabling more convenient use of nitrogen from effluent on farmland. But CARB assessed the system's financial feasibility as lower than that offered by its preferred system of moving manure to locally centralized digesters.

This article achieves five specific objectives: (1) documenting the current methane emissions of the California dairy industry, (2) describing the economic attributes of several digester technologies, (3) summarizing, in a useful framework, economic data regarding the system of digesters that CARB has identified as feasible for the San Joaquin Valley, (4) explaining and examining some key policy and economic assumptions, related to government policies on biofuel credits, that are built into CARB's economic evaluation of digesters and (5) explaining how those assumptions influence the ways in which investments in digesters may affect the economics of the California dairy industry. The overall goal of this study is to analyze and explain the economic circumstances that California dairy farms will encounter as they begin to comply with the impending regulations.

\section{Methane and livestock}

Figure 1 shows California methane emissions by source in 2013, which under SB 1383 is the benchmark year for livestock methane emission regulations, and which is used by CARB as well. Livestock accounts for $54 \%$ of California's methane emissions, primarily because the dairy industry is so large in the state.

Livestock generates methane emissions by two means: enteric fermentation and manure decomposition. Enteric fermentation creates methane in the digestive systems of ruminants such as cattle, sheep and goats. This methane is later emitted, primarily when the animals exhale or belch (Moraes et al. 2014). Methane is also generated during anaerobic (without

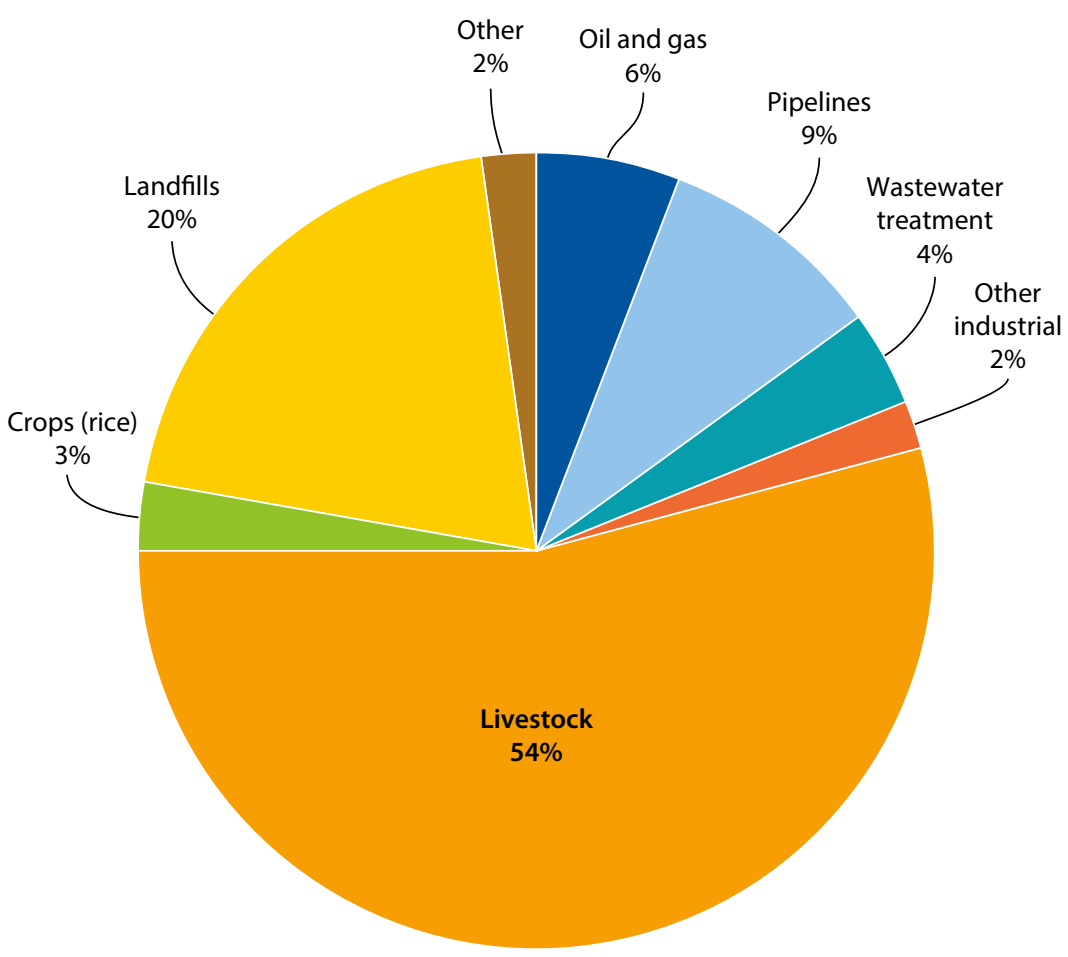

FIG. 1. California methane emissions by source in 2013 (total $=118 \mathrm{MMT} \mathrm{CO}_{2} \mathrm{e}$ ) Source: CARB (www.arb.ca.gov/cc/inventory/slcp/slcp.htm). Emission numbers for shortlived methane are based on the Global Warming Potential definition from the 2007 Intergovernmental Panel on Climate Change Fourth Assessment Report (20-year Global Warming Potential). 
air) decomposition of manure. Anaerobic decomposition of manure is common at confined animal facilities such as the many large dairies in California that process manure in lagoons.

Figure 2 breaks down by source the methane emissions associated with livestock in California. Manure handling contributes $47 \%$ of livestock methane emissions, with the dairy industry alone contributing $45 \%$. Enteric fermentation contributes the remaining 53\%, with the dairy industry accounting for $37 \%$. The dairy industry accounts for $82 \%$ of overall livestock methane emissions in the state, with the beef industry accounting for almost all of the remainder.

\section{Technologies for controlling livestock methane}

Methane emissions from enteric fermentation can be reduced by altering ruminants' diets. However, the biological relationships among emissions, health and nutrition in the context of alternative diets are complex (Liu et al. 2017; Moraes et al. 2014; Veneman et al. 2015). Research in this area is under way, but the potential to effectively and feasibly reduce methane emissions associated with enteric fermentation is currently limited. This is one reason that SB 1383 does not mandate reductions in emissions associated with enteric fermentation.

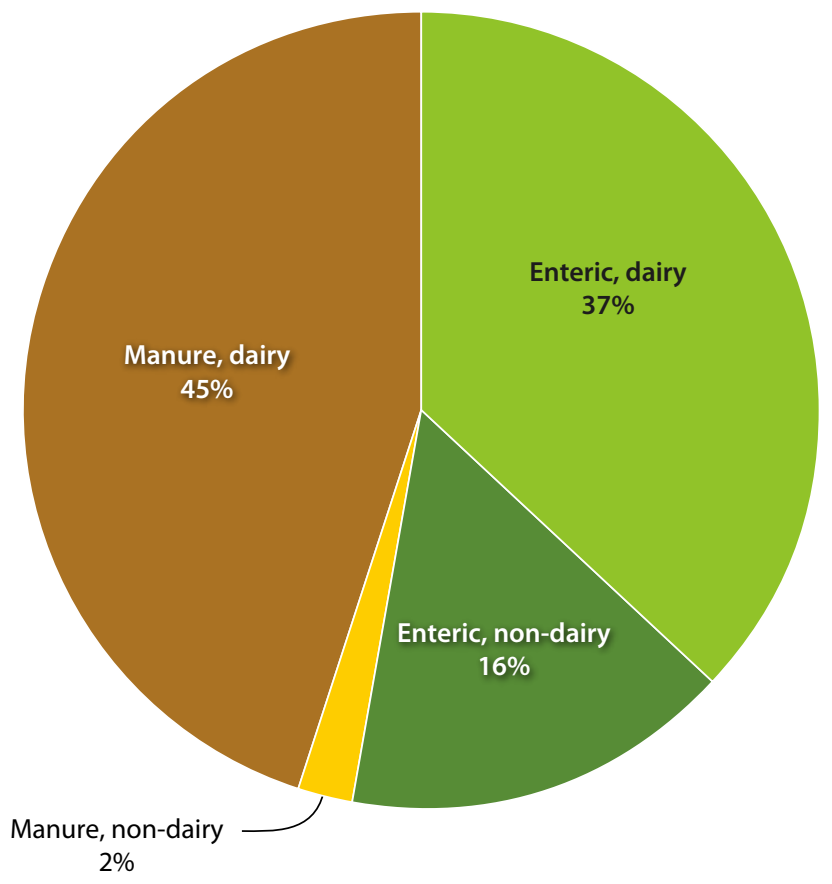

FIG. 2. California livestock methane emissions (total $\left.=64 \mathrm{MMT} \mathrm{CO}_{2} \mathrm{e}\right)$. Source: $\mathrm{CARB}$ (www.arb.ca.gov/cc/inventory/slcp/slcp.htm). Emission numbers for short-lived methane are based on the Global Warming Potential definition from the 2007 Intergovernmental Panel on Climate Change Fourth Assessment Report (20-year Global Warming Potential).
Manure-based emissions can be reduced through changes in manure management. Analysis of approaches to manure management has been under way for decades, and many technologies have been evaluated under many conditions. Recent studies have reviewed and evaluated several methods by which California dairy manure management could be modified to reduce methane emissions (CARB 2017; Kaffka et al. 2016). Methods evaluated include (1) increasing the prevalence of pasture-based dairy farming, (2) scraping and drying manure and (3) using anaerobic digestion to further process manure.

Dairy cows are often raised on pasture in places such as New Zealand and parts of Australia, and in the small dairy industry remaining in the North Coast region of California. Manure dries when left on pastures and is incorporated into the environment with little methane emission. That is also why manure-related methane emissions are low for most beef cattle in California, which are raised on pasture.

Despite its use elsewhere, pasture-based milk production is not well suited for large-scale adoption in California; it lacks economic feasibility except in specialized situations. Unlike in New Zealand, say, where the dairy system has adapted to the wet climate, California rainfall patterns create insufficient areas of high-quality pasture - especially in the major dairy region of the state, where irrigation water is limited and expensive. In addition, milk per cow is typically much lower when pasture is used for forage. In California, pasture-based dairy forage (supplemented with hay and silage) has been economically feasible only for relatively small dairies located in the North Coast region. Over time, this region's share of California milk production has declined. Pasture-based dairies in California now typically sell organic milk, or sell milk for use in specialty products destined for high-priced niche markets. Even in California locations well suited to pasturebased dairy farming, production costs are high. At California's pasture-based dairies, cost per unit of milk output is about $70 \%$ higher than the cost at confinement dairies in the San Joaquin Valley, where more than $90 \%$ of California milk is produced (CDFA 2017).

Dairies with confinement housing and herd sizes typically exceeding 1,000 cows face challenges in handling manure in environmentally sound, economically sustainable ways. One approach is to scrape manure daily from pens and barns, using vacuum trucks or mechanical scrapers (Kaffka et al. 2016), and then to dry the manure to a solid form. This approach produces lower methane emissions than does the commonly used flush-to-lagoon system, but the manure-drying process has to comply with regulations, such as building codes and local water quality rules, that prohibit leaching. The scrape-and-dry method can be costly for large commercial dairies in California (CARB 2017; Kaffka et al. 2016).

Unlike the pasture-based or the scrape-and-dry manure handling systems, anaerobic digestion allows 


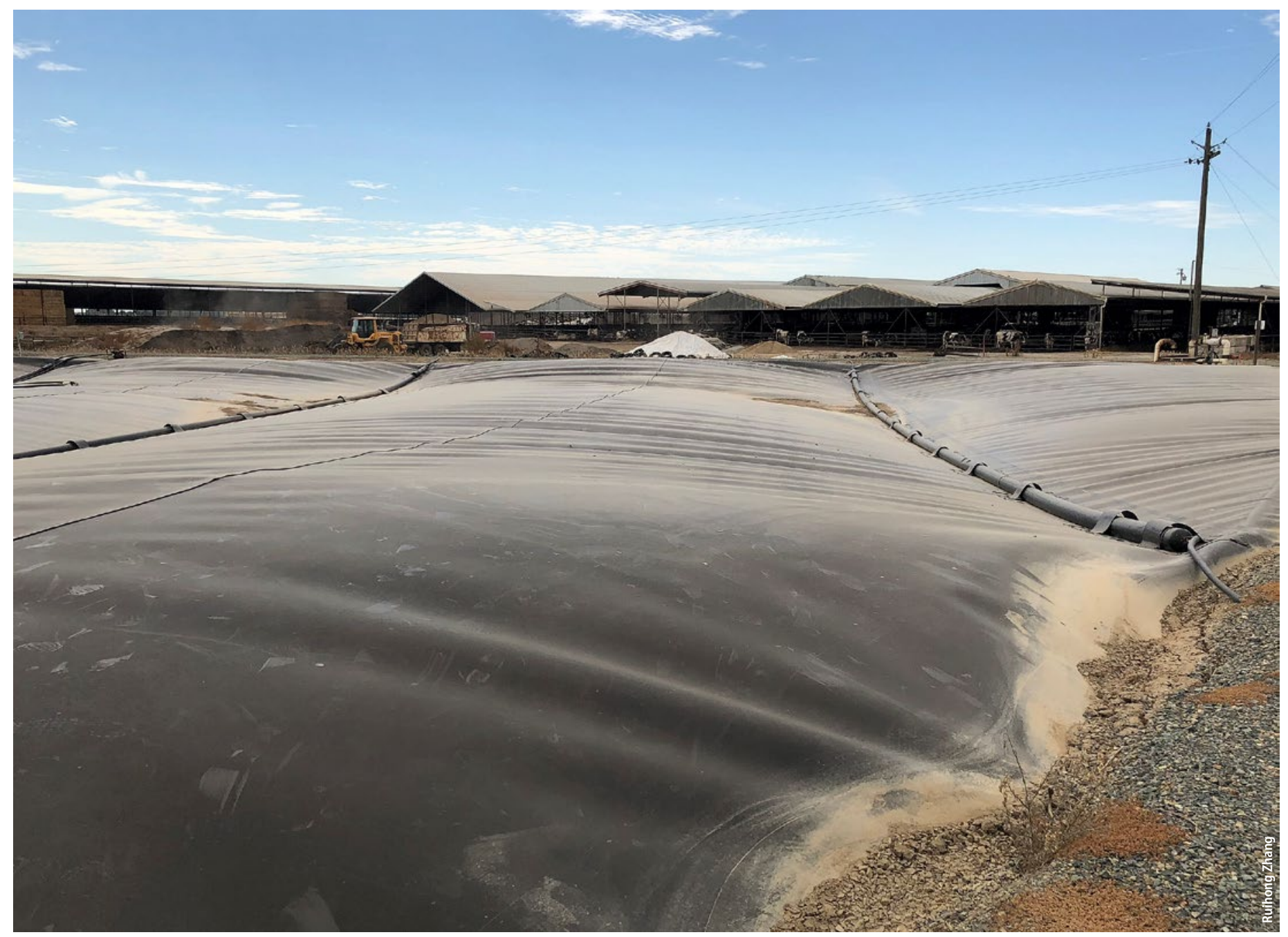

production of methane - but it recovers, or captures, the gas that would have otherwise been emitted. The captured biogas can be used to produce renewable electricity or processed to produce renewable pipelinequality natural gas (or renewable compressed natural gas). This energy can then be used in the operation on site or marketed to customers elsewhere.

Anaerobic digester technology typically requires large investments of financial and human capital. In addition, the efficient development and operation of a digester often requires substantial time and managerial expertise in an area other than dairy farming. (A detailed review of studies that discuss economies of scale and related economic issues involved in digester technology is provided by Lee and Sumner [2014]).

Nonetheless, because of its potential to produce renewable (or low-carbon) energy, the digester approach has garnered considerable attention among environmentalists, policymakers, technology advocates and potential investors (Lee and Sumner 2014).

\section{Anaerobic digester technology}

Biogas is a natural product of any anaerobic digestion of organic material. With methane as its primary component, biogas can be processed for use in several applications. It can be combusted to produce electricity, heat or both. It can be cleaned and upgraded into pipeline-quality biomethane (also known as renewable natural gas, which qualifies as a cellulosic biofuel under a federal program, the Renewable Fuel Standard [EPA $2017 b]$ ). For use in vehicles, renewable natural gas is typically compressed and used in the form of renewable compressed natural gas.

For many years, electricity has been the most common energy output produced from biogas. However, using biogas to generate electricity has been more challenging in California than in other parts of the country. Combustion of biogas during electricity generation emits nitrogen oxides (NOx) - substances regulated in locations, such as the San Joaquin Valley, that are ozone nonattainment areas under rules established by the federal Clean Air Act (EPA 2017a). Complying with NOx regulations generally requires using either costly emission control technologies or expensive electricity generation technologies such as microturbines. The need to comply with federal regulations has meant that on-farm electricity generation using biogas has been an expensive strategy for reducing dairy methane emissions in the San Joaquin Valley.
Methane captured from manure at a covered lagoon dairy digester in Sacramento County is later processed for electricity generation. In the San Joaquin Valley, the need to comply with federal airquality regulations means that using biogas for onfarm electricity generation is an expensive way to reduce dairy methane emissions. 


\section{A recent California policy change enhanced the potential payoff for dairy digesters that produce renewable natural gas.}

An alternative use for biogas is as pipeline-injectable renewable natural gas. The process of cleaning and upgrading biogas and distributing it through a pipeline, however, is quite capital intensive. With significant economies of scale, operations on a large scale are needed to reduce costs per unit. The number of cows required to reach reasonably low per-unit costs is usually greater than the number of cows at even the large California milk cow facilities. With the concentration of large dairies in the San Joaquin Valley, however, neighboring dairies can form a cluster that supplies manure as a raw material to a locally centralized digester, where biogas can be generated and processed. With a reasonable number of clusters operating in the San Joaquin Valley, locally centralized digesters may

TABLE 1. Number of digesters in California: newly constructed, shut down and operational, 2006-2018 (as of April 2018)

\begin{tabular}{|c|c|c|c|}
\hline Year & New & Shut down & Existing \\
\hline 2006 & 2 & 0 & 12 \\
\hline 2007 & 1 & 1 & 12 \\
\hline 2008 & 4 & 1 & 15 \\
\hline 2009 & 2 & 6 & 11 \\
\hline 2010 & 0 & 1 & 10 \\
\hline 2011 & 0 & 0 & 10 \\
\hline 2012 & 0 & 1 & 9 \\
\hline 2013 & 5 & 0 & 14 \\
\hline 2014 & 2 & 0 & 16 \\
\hline 2015 & 1 & 3 & 14 \\
\hline 2016 & 2 & 1 & 15 \\
\hline 2017 & 2 & 0 & 17 \\
\hline 2018 & 3 & 0 & 20 \\
\hline
\end{tabular}

Source: EPA (2018a). have the potential to curtail methane on a large scale - by as much as the $40 \%$ called for under SB 1383.

\section{History of digester investment}

Digester technology has been available and in use for decades, but it has not been widely adopted in California. All dairy digesters that have operated in California have received substantial support from federal and state government in the form of grants, favorable loan arrangements and other incentives. For

projects examined in case studies, grants have averaged more than $40 \%$ of capital cost (Lee and Sumner 2014).

Table 1, covering the period from the beginning of 2006 through April of 2018, shows how many California digesters were newly opened or shut down in each year - as well as the total number of digesters operating each year. Over this 12 -year period, new digesters were regularly built, supported by infusions of public funds. Then, after a few years, many were taken offline. All current digesters are dairy-based operations, with the number of cows ranging from 400 for a Marin County digester to 15,500 for a Kern County digester. Some facilities practice codigestion, an approach in which, along with dairy waste, other raw materials are processed. Over the 12-year period covered in the table, 24 projects were added and 14 were shut down. In the spring of 2018, 20 digesters were in operation, with the oldest four having begun operations in 2004 and the newest three added in 2018. As of this writing, six digesters were scheduled to open in 2019 (EPA 2018a). This data indicates that, despite government support, digesters in California have not yet experienced widespread adoption.

\section{Policies and programs}

A recent California policy change enhanced the potential payoff for dairy digesters that produce renewable natural gas. The California Low Carbon Fuel Standard (LCFS) Program awards tradable credits to producers of eligible low-carbon transportation fuels. In December 2015, CARB announced that California would begin to allow LCFS credits for production of vehicle fuel derived from biogas that counts toward avoided dairy methane emissions, using the ARB Livestock Offset Protocol (California Bioenergy 2015; CARB 2018a). Prior to this policy change, avoided emissions from dairy digesters could be used as carbon credits under the state's cap-and-trade program, which were worth only about one-tenth as much as the LCFS credits.

During the last few years, much government support - such as subsidies for project development efforts - has been directed to projects that produce vehicle fuel, mainly renewable compressed natural gas. In 2017, the CDFA's Dairy Digester Research and Development Program - a partnership of state, federal and local agencies - awarded financial support, totaling $\$ 35$ million, to 18 digester projects. Eleven of the 18 projects focus on producing renewable compressed natural gas, with the rest of the projects primarily used to power an ethanol refinery (CDFA 2018).

In the 2017 budget year, money available in a dairy digester fund financed by the Greenhouse Gas Reduction Fund totaled $\$ 99$ million, and of this amount, over $\$ 60$ million will be disbursed by the Dairy Digester Research and Development Program to support the construction of dairy digesters producing vehicle fuel. Several projects producing renewable compressed natural gas at commercial scale will come online soon. This is an important development for the state's greenhouse-gas mitigation efforts and for the California dairy industry, which must comply with mandates for manure-related methane reductions.

\section{Economics of renewable natural gas production}

Numerous studies have evaluated digester investments, but the following discussion focuses on recent CARB estimates of the costs and revenues associated with 
producing renewable natural gas at a cluster-based locally centralized digester (CARB 2017). Lee and Sumner (2014) have reviewed costs and returns for digester projects through 2014. Environmental Science Associates (2011) and the California Dairy Campaign (2013) have reviewed costs associated with a centralized digester system. CARB bases its estimates on a stylized 2,000-cow dairy farm; the farm participates in a cluster that operates a locally centralized digester system. CARB assumes that the San Joaquin Valley would contain 55 such local clusters, handling manure collected from a total of 1.05 million cows. This number represents almost $60 \%$ of the milk cows in California and almost two-thirds of the dairy cows in the San Joaquin Valley.

Table 2 summarizes CARB's estimates of each farm's share of the capital cost of building the locally centralized digester - a cost shared among the cluster's members - and each farm's annual flow of costs and revenues from digester operation. We begin our discussion by reviewing these cost and revenue figures.

\section{Costs}

The capital cost for the locally centralized digester system specified by CARB is about $\$ 4.8$ million for a typical farm. Capital cost is the total of the one-time expenses when the project is initiated, which include collective costs for building the digester itself, pipeline construction, manure transportation equipment and interconnection (costs to connect to and inject renewable natural gas into the main utility pipeline). Capital cost also includes the investments that each farm must make to convert to a dry-scrape system that will allow dry manure to be collected and transported to the central location. (This article evaluates the accounting and financial data that CARB presents for a system of this kind. We do not attempt to critique or evaluate other implications of the system, such as the relative costs or benefits of handling the effluent at the central location rather than at each farm.)

In addition to capital cost, each farm participating in a digester system would be responsible for a share, totaling about $\$ 588,000$, of the annual expenses associated with operating and maintaining the system (CARB 2017). Shifting to the locally centralized digester system would likely allow farms to save some of the costs associated with traditional manure handling. Although we do not have data that specifically breaks down these costs, dairy cost studies available from the CDFA indicate that average manure handling costs for large San Joaquin Valley dairies (CDFA 2017) are about $\$ 14,000$ per year.

To appreciate the financial implications for a typical dairy farm participating in a locally centralized digester system, let us view these capital and operating costs in the context of the typical farm's milk revenue. Using a 2017 average milk price of $\$ 16.50$ per hundredweight (100 pounds), a farm with 2,000 cows producing 230 hundredweight per cow per year (the average in the
San Joaquin Valley) would have annual milk revenue of almost \$7.6 million (CDFA 2017). Thus, the digester's operating costs are close to $8 \%$ of milk revenue - equal to the farm's costs for hired labor and larger than any other operating cost except for feed and replacement cows (CDFA 2017). In 2017, based on CDFA's cost estimates, average milk production and market prices, net revenue calculated at the typical dairy in the southern San Joaquin Valley amounted to zero.

The capital cost of a centralized digester $-\$ 4.8$ million - likely represents the largest single investment on a dairy farm with 2,000 cows. For comparison, if cows cost $\$ 2,000$ each, the farm's investment in 2,000 cows is $\$ 4$ million. Thus, the typical farm will invest more in the centralized digester than in the establishment of its entire herd.

\section{Revenues}

Revenue from the centralized digester includes sales of renewable natural gas and income expected from biofuel credit programs created by the California and U.S. governments. Revenue from credits created by California policy depends on specific features of the California LCFS program. Revenue from federal credits depends on features of the Renewable Fuel Standard

TABLE 2. Costs, revenues and net present value of a digester project producing pipeline-injectable natural gas, per participating farm

\begin{tabular}{|c|c|c|}
\hline Costs & Capital cost & Annual O\&M cost \\
\hline Scrape conversion & $\$ 696,000$ & $\$ 21,000$ \\
\hline Digester & $\$ 2,905,000$ & $\$ 174,000$ \\
\hline Pipeline (low pressure) & $\$ 75,000$ & $\$ 4,000$ \\
\hline Pipeline (transmission) & $\$ 104,000$ & $\$ 5,000$ \\
\hline Low NOx truck purchase & $\$ 140,000$ & - \\
\hline Manure hauling & - & $\$ 95,000$ \\
\hline Interconnection & $\$ 849,000$ & $\$ 30,000$ \\
\hline Upgrading the biogas* & - & $\$ 258,000$ \\
\hline CNG station (small fleet) & $\$ 23,000$ & $\$ 2,000$ \\
\hline Total cost & $\$ 4,792,000$ & $\$ 588,000^{\ddagger}$ \\
\hline Revenue & & Annual revenue \\
\hline Fuel sales $\left(\$ 3.46 / 1,000 \mathrm{ft}^{3}\right)$ & - & $\$ 149,000$ \\
\hline RINs ( $\$ 1.85 /$ credit) & - & $\$ 1,060,000$ \\
\hline LCFS credits ( $\$ 100 /$ credit) & - & $\$ 865,000$ \\
\hline Total revenue & - & $\$ 2,074,000$ \\
\hline Net present value ${ }^{\dagger}$ & - & $\$ 6,203,000$ \\
\hline \multicolumn{3}{|c|}{$\begin{array}{l}\text { * Capital cost for upgrading biogas is embedded in the O\&M cost. } \\
\text { † Present value calculations assume a } 10 \text {-year life for the project, a } 7 \% \text { interest rate for amortizing capital cost and a } 5 \% \\
\text { discount rate for future revenues. } \\
\text { ‡ Total differs from sum of values above due to rounding. }\end{array}$} \\
\hline \multicolumn{3}{|c|}{$\begin{array}{l}\text { F Total differs from sum of values above due } \\
\text { Source: CARB (2017), Table } 14 \text { of Appendix F. }\end{array}$} \\
\hline
\end{tabular}




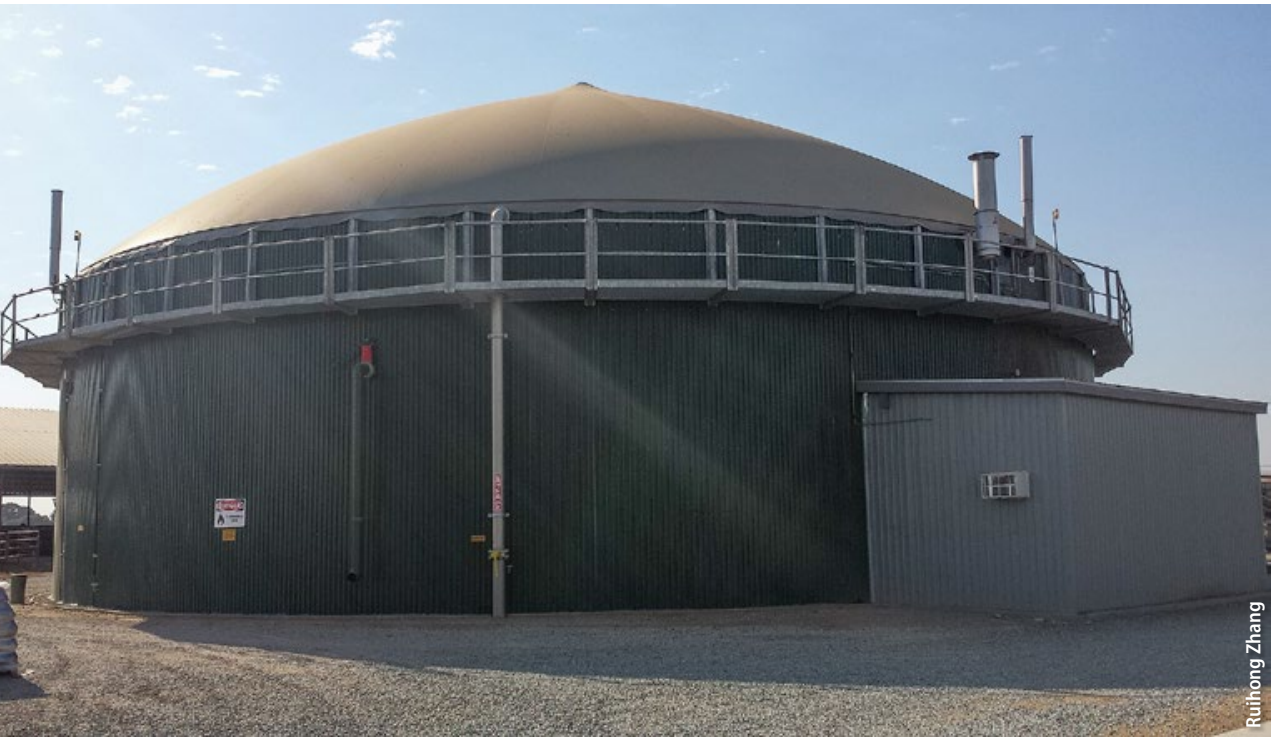

A manure digester at a dairy in Sacramento County. Because a planned system of centralized digesters in the San Joaquin Valley relies heavily on policydependent revenue streams, the system's economic viability could be vulnerable to changing political conditions.
(RFS) - also referred to as RIN credits, where "RIN" stands for "renewable identification number."

The LCFS is one of the main greenhouse-gas reduction measures adopted to implement $\mathrm{AB} 32$, the California Global Warming Solutions Act of 2006. Under the LCFS, each eligible transportation fuel is assigned a carbon intensity that indicates the fuel's estimated greenhouse-gas emissions over its life cycle - including extraction, production, transportation and consumption. LCFS credits or deficits are calculated based on each fuel's carbon-equivalent intensity (CARB 2016; CARB 2018a).

The RFS program is a national policy that requires refiners to replace a certain share of petroleum-based transportation fuel, heating oil or jet fuel with renewable fuels (EPA 2017b). Under the program, producers of renewable fuel - such as operators of centralized digesters - earn RIN credits, which can be sold to refiners to satisfy their RFS requirements (EPA 2017b). The RFS program has been controversial. It is potentially subject to substantial revision, or even elimination, by congressional or administrative action. As of this writing, in November 2018, the program is operating as usual - while the U.S. Environmental Protection Agency and congressional leaders debate whether the program will continue and, if so, in what form.

As shown in table 2, CARB estimates that annual per-farm revenues for commercial gas sales are $\$ 149,000$ (at $\$ 3.46 / 1,000$ cubic feet). For federal RIN sales (at $\$ 1.85 / 77,000 \mathrm{BTU}$ ), CARB assumes per-farm revenue of $\$ 1,060,000$. The RIN price and the associated revenue are influenced by the U.S. prices of petroleum and corn, as well as the Brazilian price of sugar cane. All these prices contribute to the price of ethanol - the dominant renewable fuel that qualifies under the program.

CARB (2017) assumes that California's LCFS credits will contribute revenue of $\$ 865,000$ (assuming $\$ 100$ per metric ton of $\mathrm{CO}_{2} \mathrm{e}$ ) to the typical farm. (As a unit of measurement, $\mathrm{CO}_{2} \mathrm{e}$ provides a common denominator for the global warming potential of different greenhouse gases. Methane is a more potent greenhouse gas than carbon dioxide; 1 metric ton of methane is equivalent to 25 metric tons of $\mathrm{CO}_{2}$.) The value of these credits depends on the equilibrium market price of emission credits in California and hence on broader supply and demand for emission credits from many sources of reduction of greenhouse gases.

Of the $\$ 2.074$ million in total annual projected revenue for the digester, only $7 \%$ comes from selling renewable natural gas in commercial markets. About 93\% of the projected revenue comes from selling government-created environmental credits. CARB estimated revenues from government programs based on the assumption that "current" prices of credits - that is, prices in April 2016, when the CARB study was initiated - were the best predictor of prices over the life of a digester project.

\section{Calculating net present value}

Any investment project must be evaluated in terms of the time paths of revenues (and other benefits) generated and expenses (and other costs) incurred during the life span of the project's capital inputs. When a project spreads over multiple time periods, it is often evaluated through a calculation of net present value. A present value of a future stream of receipts or payments over time uses an interest rate or time value of money to convert each transaction into its current equivalent; the net present value of a project is the difference between the present value of inflows and outflows over the life of the project. If the net present value is positive, the project earns a positive return above the threshold rate of return for the funds invested.

CARB's analysis of the digester project assumes a 10-year horizon for the effective economic life, including depreciation and obsolescence, of all the digester capital inputs. The net present value calculation for the digester project described above uses an amortization rate (assumed to be 7\%) to reflect the interest paid (or foregone) on the invested capital. A 5\% discount rate is used to bring the stream of net revenue over the future 10 years back to present-value terms so that it can be compared to the up-front investment. The discount rate reflects the time value of money and thus the value of foregone future investments.

Under these assumptions, CARB finds a net present value of $\$ 6.2$ million for each farm's digester investment (CARB 2017). Thus, despite large capital investments and substantial annual operating costs, projected revenues generate a very large gain for investors in a local centralized digester. The next section considers more thoroughly the assumptions that underlie this projected profitability.

\section{Alternative policy scenarios}

As noted above, projected digester revenue depends primarily on California LCFS credits and federal RIN 
credits. This dependence means that changes in state or federal policies on energy or environment issues - or even changes in the technical details of program operation - could substantially alter economic calculations pertaining to digester investment. Because digesters rely on income generated by policy-created assets, government policy risk is inherent in their revenue and profitability.

Because of the design of the LCFS and RIN programs, credit prices vary with specific market conditions such as the price of corn or oil. Moreover, the specifics of the policies change in response to political forces - and these changes can in turn affect relevant markets. We consider here several LCFS policy risk scenarios that are reflected in alternative LCFS credit prices of $\$ 120, \$ 100$ and $\$ 75$ per metric ton of $\mathrm{CO}_{2} \mathrm{e}$.

Since 2013, the market price of LCFS credits has fluctuated between $\$ 20$ and $\$ 125$ per metric ton of $\mathrm{CO}_{2}$ e. Recent prices have been relatively high, exceeding \$100 per metric ton (CARB 2018b). Smith (2016) describes a huge jump in the price of LCFS credits in 2016 - after CARB, in 2015, changed a technical detail in the LCFS formula. In light of fluctuating historical prices and the potential for further changes to the formula, we chose a range from $\$ 120$ to $\$ 75$ to represent the upside and downside market risk relative to CARB's reference price for LCFS credits $-\$ 100$ per metric ton.

Historical RIN prices have also fluctuated. Out of four categories of RINs, renewable natural gas belongs to the highest-priced category (known as D3 RIN, or cellulosic RIN). The credit price for D3 RIN is determined by adding a cellulosic waiver credit, which is set annually by formula pricing (Sheehy and Rosenfeld 2017), to the market-determined price of D5 RINs. The cellulosic waiver credit represents the lion's share of the value of D3 RINs. Over the last 4 years, the D5 RIN price has fallen in the range of 60 to 80 cents whereas the cellulosic waiver credit has ranged between
64 cents and $\$ 2$ (64 cents in 2015, \$1.33 in 2016, \$2 in 2017 and $\$ 1.96$ in 2018) (EPA 2018b).

The major risk associated with the value of RIN credits lies in the risk that features of renewable fuel standards will change, perhaps substantially. The RFS program, which authorizes RIN credits, is more politically vulnerable than the LCFS program. The risks potentially include elimination of the program (Wall Street Journal 2018). To account for recent trends in pricing of credits and for uncertainty surrounding the policies that will affect future RIN credits, we develop scenarios in which revenue associated with RIN credits increases by $25 \%$ - or decreases by $25 \%, 50 \%$, $75 \%$ or $100 \%$ - from the baseline assumed by CARB. Digesters would receive no RIN revenue if the federal RFS program were eliminated or if it were changed so that benefits for the California manure digester program were removed.

Finally, our revenue scenarios are developed under two overarching California LCFS credit regimes, which we call "pre-regulation" and "post-regulation." These two regimes are distinct periods falling before and after mandatory regulations are fully implemented - which, under SB 1383, is scheduled for 2024. During the preregulation period, methane reduction is not mandatory - and avoided methane emissions are thus credited for LCFS credit calculations. During the post-regulation period, when methane reduction is mandatory, avoided methane emissions no longer earn LCFS credits. In other words, credits are awarded against a baseline and the baseline changes once mandatory regulations take effect.

According to CARB data, the applicable carbon intensity of manure-based biofuel would increase after regulation to $13 \mathrm{gCO}_{2} \mathrm{e}$ per megajoule from $-276 \mathrm{gCO}_{2} \mathrm{e}$ per megajoule. This increase in carbon intensity would lower LCFS credit revenue for manure-based biofuel to $\$ 110,000$ per year from $\$ 865,000$ per year, meaning that

TABLE 3. Net present values (\$ million) corresponding to alternative LCFS price and RIN revenue scenarios under pre- and post-regulation conditions

\begin{tabular}{|c|c|c|c|c|c|c|}
\hline & \multicolumn{6}{|c|}{ LCFS credit price } \\
\hline & $\$ 120$ & $\$ 100$ & $\$ 75$ & $\$ 120$ & $\$ 100$ & $\$ 75$ \\
\hline & \multicolumn{3}{|c|}{ Pre-regulation $\left(\mathrm{Cl}=-276 \mathrm{gCO}_{2} / \mathrm{MJ}\right)$} & \multicolumn{3}{|c|}{ Post-regulation $\left(\mathrm{Cl}=13 \mathrm{gCO}_{2} / \mathrm{MJ}\right)$} \\
\hline RIN revenue $125 \% *$ & $\$ 9.59$ & $\$ 8.25$ & $\$ 6.58$ & $\$ 2.61$ & $\$ 2.41$ & $\$ 2.21$ \\
\hline RIN revenue $100 \%$ & $\$ 7.54$ & $\$ 6.20$ & $\$ 4.54$ & $\$ 0.55$ & $\$ 0.37$ & $\$ 0.16$ \\
\hline RIN revenue $75 \%$ & $\$ 5.50$ & $\$ 4.16$ & $\$ 2.49$ & $-\$ 1.50$ & $-\$ 1.67$ & $-\$ 1.89$ \\
\hline RIN revenue $50 \%$ & $\$ 3.45$ & $\$ 2.11$ & $\$ 0.44$ & $-\$ 3.55$ & $-\$ 3.72$ & $-\$ 3.93$ \\
\hline RIN revenue $25 \%$ & $\$ 1.40$ & $\$ 0.07$ & $-\$ 1.60$ & $-\$ 5.59$ & $-\$ 5.76$ & $-\$ 5.98$ \\
\hline $\begin{array}{l}\text { RIN completely } \\
\text { removed }\end{array}$ & $-\$ 0.64$ & $-\$ 1.98$ & $-\$ 3.65$ & $-\$ 7.64$ & $-\$ 7.81$ & $-\$ 8.02$ \\
\hline
\end{tabular}

* Proportion of CARB's reference RIN revenue.

Source: Authors' calculation. 
manure-based fuels would earn only $13 \%$ of the LCFS credits that they earned before regulation (CARB 2017). According to CARB (2017), projects that begin to operate before reduced methane emissions become mandatory may apply the pre-regulation carbon intensity to their credit calculations for the full 10-year life of the digester system (CARB 2017, Appendix F, 11).

Table 3 shows the effects on net present value that result from several scenarios involving potential LCFS credit prices and RIN revenues. In order to facilitate comparisons, we highlight a reference scenario under which the LCFS credit price is $\$ 100$, RIN revenue remains at $100 \%$ of its currently assumed level and net present value is $\$ 6.2$ million. Under the pre-regulation regime, almost all scenarios generate positive net present values. The exceptions are scenarios that assume either elimination of RIN credits or a $75 \%$ reduction in revenue from both RIN and LCFS credits. The post-regulation regime scenarios, however, with their large reductions in LCFS revenue, yield much lower and often negative net present values. Under this regime, positive net present values occur only when RIN revenue is at least equal to the reference level (100\%) assumed by CARB. Under the post-regulation regime, RIN income becomes even more crucial to establishing positive net present value, highlighting the significance of RFS policy risk.

Policy changes can flow from political realignments or from new technical information. Given the complexity of the LCFS and RFS policies, even small technical adjustments to regulations can have major effects on policy-generated revenues. In 2016, for example, California adjusted certain details of LCFS calculations - details involving indirect land-use impacts and the carbon intensity of crop-based biofuel. This adjustment resulted in a higher implied carbon intensity for cornbased ethanol and thus a reduction in LCFS credits per unit of ethanol (Smith 2016). This change in a technical detail created a market shortage in the supply of LCFS credits. In the first quarter of 2016, the shortage caused the market price for credits to increase to as much as $\$ 123$ per ton from about $\$ 20$ per ton (Smith 2016). Such technical adjustments can cause decreases in price just as easily as increases in price. The adjustments may involve seemingly minor details, unrelated to digesters or even to conditions in California.

Federal RFS policy, which creates value for RINs, has come under increasing political pressure as ethanol's environmental contributions have been questioned (Smith 2016). In the long term, RIN credits are much more critical than LCFS credits to digester revenue. If only $13 \%$ of pre-regulation LCFS credits are available to a digester that comes online after implementation of California's mandatory regulation of dairy methane, revenue from federal RIN credits would account for more than $80 \%$ of the digester's revenue. Therefore, the economic viability of newly built digesters under the post-regulation regime depends crucially on revenue from the federal program.
For locally centralized digester systems, economic viability clearly requires that certain policies remain largely unchanged. Investment in digester systems therefore depends on investor willingness to accept policy risk as a major economic consideration. In that context, if the California government wants to encourage investment in such projects, it might wish to consider establishing government assurances, or a government-backed insurance program, to cover losses associated with possible changes in state or federal policies.

A final investment issue concerns market-based uncertainty related to the scale of digester projects and the future economic health of the dairy industry in the San Joaquin Valley. Locally centralized digester systems producing pipeline-injectable biogas require a large up-front capital investment, which implies substantial scale economies. In California, however, the numbers of dairy cows - after rising rapidly until 2007 - have been declining gradually for more than a decade, as other dairy states have become more efficient (CDFA 2016). If dairy operations face additional costs due to implementation of greenhouse-gas rules or other regulations, further decreases in the number of cows are likely. If neighboring farms that co-invest in a digester project exit, the remaining farms will face higher costs. In-depth analysis of a potential digester investment must incorporate the probability that neighbors and their cows may leave, causing a risk that the per-farm costs assumed in table 2 may be too low.

As noted above, our analysis is limited to the emission reduction pathway, which assumes that manure is scraped and hauled to a locally centralized facility to produce pipeline-quality natural gas. Further research should examine alternative pathways, such as on-farm digesters connected to a central facility for compressed natural gas, where biogas is conditioned and upgraded. Such research would provide a fuller assessment of the potential economic consequences of the new policies.

\section{Policy risk threatens investment}

Developing cluster-based, anaerobic, locally centralized digester systems - systems that produce renewable natural gas - may offer the California dairy industry an economically viable way to comply with mandatory methane regulations. Investment in such projects, however, requires a large commitment of capital compared to other dairy investments. Investing in a digester also involves considerable uncertainty - uncertainty that falls outside the variability in milk and feed markets that farmers have long been familiar with. Issues outside the farmer's control that affect a digester's payoff include unfamiliar technical specifications and operational details, variable energy prices and unexpected shifts in, or rapidly evolving, state and national regulations and policies. For any investment whose economic outcome depends primarily on continuation of favorable government policies, long-term 
assurance of and clarity regarding policy are crucial. A policy under which the government assumes some of the downside policy risk could enhance confidence in revenue stability.

Under California's evolving methane regulations, emissions from manure handling must be reduced.

Any net cost involved in achieving low greenhouse-gas emissions can be considered part of the routine cost of milk production and processing in California. If costs are added to those already borne by dairy farms and processors, the California dairy industry will find it more challenging to maintain national and global competitiveness. Unless handled carefully, new methane regulations could erode the economic position of dairy farms and processors in California. If that were to happen, we would expect additional exits from the industry or relocation out of California, resulting in reduced dairy-related economic activity, especially in the San Joaquin Valley (Medellín-Azuara et al. 2018; Sumner et al. 2015). The potential for such a downward spiral deserves careful consideration.

We document the crucial role of policy-generated income and risks inherent in such income. Dairy digesters can survive or even thrive in California if policy uncertainty is mitigated and policy-generated revenue flows are assured. Without such assurances, or some other source of revenue or government funds to cover invested capital, digesters may be too risky to warrant investment. If they are not carefully implemented, California regulations will fail to reduce global greenhouse-gas emissions - indeed, they will simply shift methane emissions to other locations while also eroding the economic viability of the California dairy industry. CA

H. Lee is Agricultural Economist in the Department of Agricultural and Resource Economics at UC Davis, and D.A. Sumner is UC Agricultural Issues Center Director and Frank H. Buck Jr. Professor in the Department of Agricultural and Resource Economics at UC Davis.

\section{References}

California Bioenergy. 2015 Staff Summary Method 2b Application: Prospective Pathway Dairy Biogas to CNG. www.arb. ca.gov/fuels/lcfs/2a2b/apps/ calbio-sum-122115.pdf California Dairy Campaign. 2013. Economic Feasibility of Dairy Digester Clusters in California: A Case Study. https:// archive.epa.gov/region9/ organics/web/pdf/cba-session2-econ-feas-dairy-digesterclusters.pdf

[CARB] California Air Resources Board. 2016. Low Carbon Fuel Standard Program Background. www.arb.ca.gov/fuels/lcfs/lcfsbackground.htm (accessed Oct. 5, 2017)

CARB. 2017. Short-Lived Climate Pollutant Reduction Strategy. Sacramento, CA: CARB. 145 p. www.arb.ca.gov/cc/shortlived/ meetings/03142017/final_slcp_ report.pdf

CARB. 2018a. LCFS Pathway Certified Carbon Intensities. www. arb.ca.gov/fuels/lcfs/fuelpathways/pathwaytable.htm

CARB. 2018b. LCFS Credit Transfer Activity Reports. www. arb.ca.gov/fuels/lcfs/credit/ Irtcreditreports.htm (accessed Apr. 10, 2018)
[CDFA] California Department of Food and Agriculture. 2016. California Dairy Statistics Annual 2016. www.cdfa.ca.gov/dairy/ pdf/Annual/2016/2016_Statis tics_Annual.pdf (accessed Oct. 5, 2017).

CDFA. 2017. Statewide Cost Comparison Summary, 2017 Second Quarter Cost Comparison. www.cdfa.ca.gov/dairy/uploader/docs/CA_2017_Q2_WEB pdf (accessed Oct. 5, 2017).

CDFA. 2018. Dairy Digester Research \& Development Program. www.cdfa.ca.gov/oefi/ ddrdp

Environmental Science Associates. 2011. Economic Feasibility of Dairy Manure Digester and

Co-Digester Facilities in the Central Valley of California. Sacramento, CA: Environmental Science Associates. 408 p. www.waterboards.ca.gov/ centralvalley/water_issues/ confined animal facilities/program_regs_requirements/dairy/ final_dairy_digstr_econ_rpt.pdf [EPA] Environmental Protection Agency. 2017a. Air Actions in the San Joaquin Valley Ozone. www3.epa.gov/region9/ air/sjvalley/ (accessed Oct. 5, 2017).
EPA. 2017b. Renewable Fuel Standard Program. www.epa. gov/renewable-fuel-standardprogram/overview-renewablefuel-standard (accessed Oct. 5, 2017).

EPA. 2018a. AgSTAR: Livestock Anaerobic Digester Database. www.epa.gov/agstar/livestock anaerobic-digester-database (accessed July 25, 2018).

EPA. 2018b. Cellulosic Waiver Credits Purchased Annually. www.epa.gov/ fuels-registration-reportingand-compliance-help/ cellulosic-waiver-credits-purchased-annually (accessed Aug 25, 2018)

Kaffka S, Barzee T, El-Mashad H, et al. 2016. Evaluation of Dairy Manure Management Practices for Greenhouse Gas Emissions Mitigation in California. Final technical report to the State of California Air Resources Board. https://biomass.ucdavis.edu/ wp-content/uploads/ARBReport-Final-Draft-TransmittalFeb-26-2016.pdf

Lara R. Chapter 395, Statutes of 2016. www.leginfo.ca.gov/ pub/15-16/bill/sen/sb 1351 1400/sb_1383_bill_20160919 chaptered.htm
Lee H, Sumner D. 2014.

Greenhouse Gas Mitigation Opportunities for California Agriculture: Review of the Economics. Nicholas Institute Report NI GGMOCA R7, Duke Nicholas Institute for Environmental Policy Solutions. https://nicholasinstitute.duke. edu/ecosystem/publications/ greenhouse-gas-mitigationopportunities-california-agricul ture-review-economics

Liu Z, Liu Y, Murphy JP, Maghirang R. 2017. Ammonia and methane emission factors from cattle operations expressed as losses of dietary nutrient or energy. Agriculture 7(3). doi:10.3390/agriculture7030016

Medellín-Azuara J, Sumner D, Pan QY, et al. 2018. Assessment of California Crop and Livestock Potential Adaptation to Climate Change. California Natural Resources Agency.

Publication number: CCCA4CNRA-2018-018. http://climateassessment.ca.gov/techreports/ docs/20180827-Agriculture CCCA4-CNRA-2018-018.pdf

Moraes LE, Strathe AB, Fadel JG, et al. 2014. Prediction of enteric methane emissions from cattle. Glob Change Biol 20(7):2140-8. doi:10.1111/gcb.12471
Sheehy P, Rosenfeld J. 2017. Overview of Renewable Fue Standard. https://arb.ca.gov/cc/ dairy/documents/09-07-17/icfpresentation-090717.pdf Smith A. 2016. Biofuel policies: Robbing Peter to pay Paul. ARE Update 19(3). https://s.giannini. ucop.edu/uploads/giannini_ public/90/31/90317b32-3df54835-b1cd-91ed9488d419/ v19n3_1.pdf

Sumner D, Medellín-Azuara J, Coughlin E. 2015. Contributions of the California Dairy Industry to the California Economy. http://aic.ucdavis.edu/publications/CMABReport2015.pdf

Veneman JB, Muetzel S, Hart $\mathrm{KJ}$, et al. 2015. Does dietary mitigation of enteric methane production affect rumen func tion and animal productivity in dairy cows? PLOS ONE 10(10):e0140282. https:// doi.org/10.1371/journal. pone.0140282

Wall Street Journal. 2018. You RIN some, you lose some. Editorial, March 12. www.wsj.com/ articles/you-rin-some-you-losesome-1520897397 